\title{
Optimization of Enzymatic-assisted Extraction of Polysaccharides from Roxburgh Rose Pomace and its Antioxidant Activity
}

\author{
Xiaoli ZHOU*, Guangxu ZHU, Yansheng YANG, Bin DU, Dong LIN \\ College of Food and Pharmacy Engineering, Guiyang University, Guiyang, 550005, China;
}

\begin{abstract}
In this experiment, at first the roxburgh rose juice was extracted and then roxburgh rose residue was taken as raw material. We have used the enzyme assisted method to study the extraction process of polysaccharides from roxburgh rose pomace. The effects of mesh number, the concentration of the enzyme, temperature and time, $\mathrm{pH}$ and solid-liquid ratio on the polysaccharides yield were explored by single factor experiments. And then orthogonal experiment was designed to study the optimal techniques on extracting of polysaccharides from pomace. The in vitro antioxidant activity of the obtained polysaccharides was studied. The results showed that the optimal condition of extracting polysaccharides was as follows: enzyme concentration $2.5 \%$, enzymatic hydrolysis at $60^{\circ} \mathrm{C}$ for $40 \mathrm{~min}, \mathrm{pH} 4.0$, mesh number were 100 and solidliquid ratio was $1: 25$ based on the ratio of cellulase and pectinase was 2: 1 . The average polysaccharides yield of enzymatic extraction method reached ( $4.79 \pm 0.07) \%$ under the optimal condition. The antioxidant activity assays in vitro revealed that polysaccharides from roxburgh rose pomace can be used as natural antioxidants in functional foods and pharmaceutical industries.
\end{abstract}

\section{Introdution}

Plant polysaccharides are polymers of monosaccharides units joined together, which are widely found in plant cell wall and animal cell membranes in nature [1,2]. Studies on polysaccharide activity have found that it involved in many complex bioactivity and functions such as cell recognition, growth, differentiation, metabolism and so on [2-4]. It also has anti-tumor, antioxidation, regulating serum lipid and other bioactivities. As one of the main nutritional or pharmacological components of roxburgh rose, polysaccharide of roxburgh rose has many bioactivities, such as antioxidation, immunomodulation, delaying the aging process and so on [5-7]. It has good value of development and utilization in the human body.

At present, the cultivation of roxburgh rose is mainly concentrated in the southwest of China, the output of roxburgh rose in Guizhou ranks first in China [8]. Therefore, it has great significance to develop local characteristic resources. Recent studies on roxburgh rose have shown that it contains vitamin $\mathrm{C}$, organic acids, polysaccharides and other active components [6,7], which is widely used in the fields of health products and medicine [7-9]. Yet, with the development of juice processing in China, roxburgh rose residue which after roxburgh rose juicing nearly $50 \%$ each year $[8,9]$, it is also used as cattle feed or directly disposed as waste. The polysaccharides in the residue were discarded, resulting in the waste of resources. Therefore, it has certain social values as well as some economic benefits to discuss the utilization method of residue resources from roxburgh rose. Therefore, there has been increasing interest in developing and utilizing natural, effective and safe antioxidants, such as plant polysaccharides, to protect the human body from chronic. Enzymatic assisted extraction of polysaccharides has the advantages of mild conditions, easy removal of impurities and high yield $[10,11]$.

In this study, the processing waste residue of roxburgh rose in Longli County of Guizhou province was used as raw material, and then orthogonal experiment was designed to study the optimal techniques on extracting of polysaccharides from pomace by cellulase and pectinase. The in vitro antioxidant activity of the obtained polysaccharides was studied. It not only reduced waste and pollution to the environment, but also provides the theoretical basis for the comprehensive utilization of the roxburgh rose residue resources so as to achieve the purpose of high value conversion and utilization.

\section{Materials and Methods}

The roxburgh rose residue was collected in the Longli County (Guizhou province, China) in September 2016, which after roxburgh rose juice was taken to microwave vacuum, drying, and stored at $-20^{\circ} \mathrm{C}$ until it was used for the purpose of experiment.

\footnotetext{
* Corresponding author: lizi008009@126.com
} 


\subsection{Extraction of crude polysaccharide from roxburgh rose residue}

The dried roxburgh rose residue was crushed and sifted, $2 \mathrm{~g}$ residue was extracted with cellulase and pectinase according to the parameters set by single factor experiment [10]. Then later on it was precipitated by the addition of ethanol and kept for the whole night, the supernatant was discarded after centrifugation at 6000 rpm for $20 \mathrm{~min}$, it was washed with absolute ethanol, then centrifuged, and the ethanol washing step was repeated twice, the crude polysaccharide A after freezedried.

The crude polysaccharide was re-dissolved in distilled water for degreasing and removing protein by add 3 times volume of petroleum ether $(3: 1 \mathrm{v} / \mathrm{v})$ and sevag (Chloroform: n-butanol =4: 1) method [10,12,13], then precipitated by the addition of ethanol overnight, the supernatant was discarded after centrifugation at $6000 \mathrm{rpm}$ for $20 \mathrm{~min}$, it was washed with absolute ethanol, then centrifuged, and this ethanol washing step was repeated twice, the crude polysaccharide B after freeze-dried.

\subsection{Determination of polysaccharide content}

The absorbance of each sample was determined by sulfuric acid-phenol method $[14,15]$.

\subsection{Single Factor Experiment}

Accurately weighing $2.00 \mathrm{~g}$ roxburgh rose pomace which dry and sifting $(40,60,80,100,120$ mesh), add distilled water $(1: 15,1: 20,1: 25 、 1: 30 、 1: 35 \mathrm{~g} / \mathrm{mL}$ at the solidliquid ratio), $(0.5,1,1.5,2,2.5 \%)$ cellulase and pectinase and adjust $\mathrm{pH}(4,5,6,7,8)$, then enzymatic hydrolysis at $40,45,50,55,60{ }^{\circ} \mathrm{C}$ for $40,60,80,100$ or $120 \mathrm{~min}$, separately. The content of polysaccharide in supernatant after $15 \mathrm{~min}$ in the boiling water bath was determinated. Study on the effects of enzymatic concentration, enzymatic hydrolysis time and temperature, solid-liquid ratio, $\mathrm{pH}$ and mesh on the yield of polysaccharide from roxburgh rose pomace was conducted.

\subsection{Orthogonal Experiments}

The yield of crude polysaccharides from roxburgh rose pomace was taken as the index on the basis of single factor experiment, and the optimal techniques on extracting of polysaccharides from pomace by orthogonal experiments with six factors and three levels $\mathrm{L}_{18}\left(3^{6}\right)$, the factor level was shown in Table 1.

Table 1 Factors and levels of orthogonal experiment

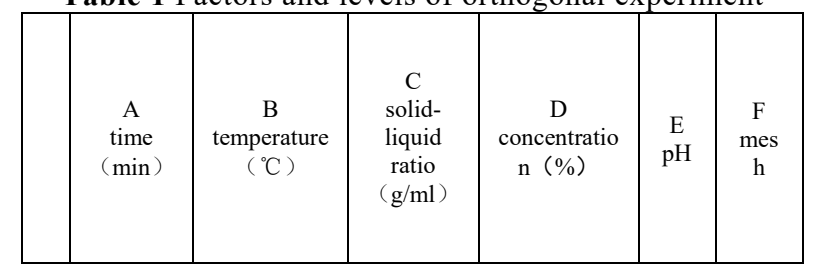

\begin{tabular}{|c|c|c|c|c|c|c|}
\hline 1 & 40 & 50 & $1: 25$ & 1.5 & 4 & 60 \\
\hline 2 & 60 & 55 & $1: 30$ & 2.0 & 5 & 80 \\
\hline 3 & 80 & 60 & $1: 35$ & 2.5 & 6 & 100 \\
\hline
\end{tabular}

\subsection{Analysis of antioxidative properties of polysaccharide from roxburgh rose pomace}

The crude polysaccharide A and B was re-dissolved in distilled water for antioxidant activity.

\subsubsection{Reduction power}

Making accurate shift polysaccharide samples from roxburgh rose pomace, followed by adding $2.5 \mathrm{~mL}$ $0.2 \mathrm{~mol} / \mathrm{L}$ phosphate buffer solution and $2.5 \mathrm{~mL} 1 \%$ six potassium dicyanate solution, and rapid cooling after reaction $20 \mathrm{~min}$ at $50^{\circ} \mathrm{C}$, then adding $2.5 \mathrm{~mL} 10 \%$ three trichloroacetic acid and centrifugation at $3000 \mathrm{rpm}$ for $10 \mathrm{~min}$, the supernatant was added in $2.5 \mathrm{~mL}$ distilled water and $0.5 \mathrm{~mL} 0.1 \%$ trichloride solution, and then the absorption was measured at the wavelength of $700 \mathrm{~nm}$ after statically placing $10 \mathrm{~min}$.

\subsubsection{Scavenging hydroxyl radical $(\cdot \mathrm{OH})$ activity}

$2 \mathrm{~mL} 9 \mathrm{mmol} / \mathrm{L} \mathrm{FeSO}_{4}, 2 \mathrm{~mL} 9 \mathrm{mmol} / \mathrm{L}$ salicylic acid and $2 \mathrm{~mL}$ sample solution were successively added to the tube with stopper. The absorptivity was measured at $510 \mathrm{~nm}$ after water bath reaction for 30 minutes at $37{ }^{\circ} \mathrm{C}$ by adding $2 \mathrm{~mL} 8.8 \mathrm{mmol} / \mathrm{L} \mathrm{H}_{2} \mathrm{O}_{2}$ [16].

\subsubsection{Scavenging activity of DPPH radical}

0.1984g 2,2-diphenyl-1-picrylhydrazyl (DPPH) was accurately weighed and dissolved with anhydrous ethanol to $50 \mathrm{~mL}$ as reserve liquid, then $2 \mathrm{~mL} \mathrm{DPPH}$ reserve solution was dissolved in absolute ethanol. $2 \mathrm{~mL}$ DPPH solution and $2 \mathrm{~mL}$ ethanol as the test tube, the absorptivity was determined at $517 \mathrm{~nm}$ after light avoidance reaction [17].

\subsection{Statistical analysis}

Values are expressed as mean +/- standard deviation. Statistical analyses were performed by one-way analysis of variance with the Duncan's multiple range test (SPSS 17.0, Illinois, USA). $\mathrm{P}$ values of less than 0.05 were considered statistically significant.

\section{Results and Discussion}

\subsection{Determination of optimal proportion of enzymes}


Taking $2.00 \mathrm{~g}$ dry and mesh 80 of roxburgh rose pomace, adjust solution $\mathrm{pH} 5$, then adding distilled water according to $1: 20 \mathrm{~g} / \mathrm{mL}$, and $2 \%$ the ratio of cellulase and pectinase enzyme solution was 1:1, 1:2, 2:1, respectively. As can be seen from figure 1, when the ratio of cellulase to pectinase is $2: 1$, the polysaccharide yield is significantly higher than that of the other two groups $(\mathrm{p}<0.05)$. Therefore, in the following experiment, the compound enzyme was used to assist the extraction of polysaccharides from pomace at the ratio of cellulase and pectinase is $2: 1$.

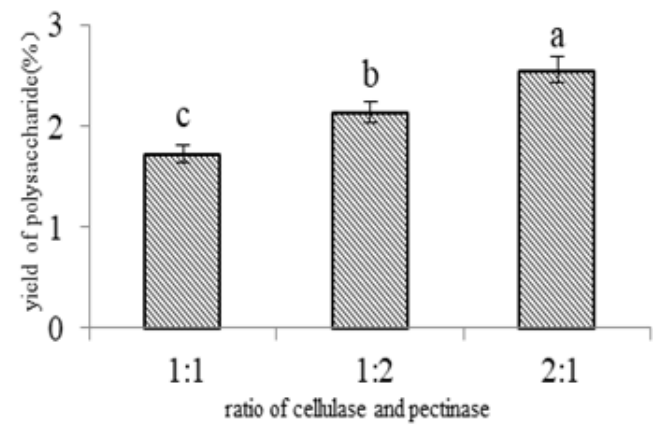

Fig.1 Effect of the ratio of cellulase and pectinase on the yield of polysaccharide

Values with different superscripts within a column are significantly different $(\mathrm{P}<0.05)$. All measures were performed in three independent samples.

\subsection{Single factor experiments}

\subsubsection{Effect of enzymatic hydrolysis time on the yield of polysaccharides from roxburgh rose pomace}

In the reaction process of enzymatic hydrolysis, the yield of polysaccharides changed with the continuous extension of extraction time, reaching up to equilibrium. As it is shown in figure 2(a), along with the increase of reaction time, the yield of polysaccharides increased gradually. The content of polysaccharides reached the maximum when the system was heated for $60 \mathrm{~min}$. The cellulase and pectinase tend to lose their bioactivity for a long time heating, moreover the dissolution of polysaccharides tends to balance after reaching the highest, which leads to the decrease of polysaccharide content. Yet, the reaction system may be basically balanced after 80 minutes, and there is no significant difference between the latter three groups $(\mathrm{p}>0.05)$.

\subsubsection{Effect of enzymolysis temperature on the yield of polysaccharides from roxburgh rose pomace}

With the increase of enzymatic hydrolysis temperature, the content of polysaccharides increased gradually. As the figure below shows clearly, it is not conducive to the dissolution of polysaccharides when the temperature is lower than $45{ }^{\circ} \mathrm{C}$; when the enzymatic hydrolysis temperature reached $55{ }^{\circ} \mathrm{C}$, the content of polysaccharides ranked highest, it maybe the high temperature which might promote the movement rate of molecules. Shortly the content of polysaccharide decreased, yet the difference was not distinguished $(\mathrm{p}>0.05)$. Since the temperature will affect the activity of enzyme in a certain temperature range, the reaction rate of enzyme will increase with the increase of temperature, thus accelerating the decomposition of substrate. When the heating temperature is too high, the enzyme activity will be weakened or even lost, the reaction rate will be slowed down and the polysaccharide will decompose due to its thermal instability, which will lead to the decrease of polysaccharide yield.

\subsubsection{Effect of solid-liquid ratio on the yield of polysaccharides from roxburgh rose pomace}

From figure 2(c), the content of polysaccharides extracted from pomace increased with the increase of the solid-liquid ratio; the content of polysaccharide increased significantly when the solid-liquid ratio is $1: 30(p<0.05)$. The yield decreased at radio of $1: 35$, but the difference was not significant $(p>0.05)$. It is suggested that when the solid-liquid ratio is too low, it is not conducive for the full dissolution of roxburgh rose pomace. Only when the solid-liquid ratio is appropriate, the swelling ability of the raw material cells get enhanced, it promoted the permeation of compound enzymes and solvents to the roxburgh rose pomace effectively, resulted the yield of polysaccharide increased [3]. The solid-liquid ratio too high may lead to the dissolution of other impurities, thus affecting the yield of polysaccharides, but also lead to the follow-up enrichment process cumbersome.

\subsubsection{Effect of mesh on yield of polysaccharides from roxburgh rose pomace}

the content of polysaccharides got ascent first and then fell with the increase of mesh. When the degree of comminution reached 100 mesh, the polysaccharide content was significantly higher than others $(p<0.05)$, then the yield decreased sharply $(p<0.05)$. Therefore, 100 mesh can be obtained as the optimum for extraction.

\subsubsection{Effect of enzymatic concentration on yield of polysaccharides from roxburgh rose pomace}

Accordingly, cellulase and pectinase can effectively destroy or decomposition cell wall of roxburgh rose pomace, which is helpful to improve the extraction rate of polysaccharide. Just as what is shown below in figure 2(e), the content of polysaccharides raised with the increase of the concentration of enzyme. When the concentration was $1.5 \%-2.0 \%$, the yield was significantly higher than that of the other groups $(p<0.05)$; then the yield significantly decreased $(p<0.05)$, due to a certain substrate concentration in this experiment has reached saturation. 


\subsubsection{Effect of $\mathrm{pH}$ on yield of polysaccharides from} roxburgh rose pomace

When $\mathrm{pH}$ was $4-5$, the polysaccharide content was significantly higher than that of other groups $(p<0.05)$; the extraction rate of polysaccharides tends to decrease with the $\mathrm{pH}$ value of the solution continues to increase $(\mathrm{p}<0.05)$. This may be due to the $\mathrm{pH}$ restricted the enzyme activity, and cellulase and pectinase activity is stronger under the condition of partial acidity, which is helpful to the extraction of polysaccharides. When the solution was neutral or alkaline, the enzyme was inactivated, and the polysaccharide content was significantly lower than that in other groups $(\mathrm{p}<0.05)$.

\subsection{Orthogonal experiment}

The effects of mesh number, the quantity of the enzyme, temperature and time, $\mathrm{pH}$ and solid-liquid ratio on the polysaccharides yield were explored by single factor experiments. And then orthogonal experiment was designed to study the optimal techniques on extracting of polysaccharides from roxburgh rose pomace. The orthogonal optimization test is carried out according to the three optimal levels determined by the single factor experiments, and the design is shown above in table 1. The experimental results and intuitive analysis are shown below in table 2, affecting the content of polysaccharides which was extracted from pomace by enzyme assisted method, that is, enzymatic concentration $>$ enzymatic hydrolysis time $>$ enzymatic hydrolysis temperature $>$ solid-liquid ratio $>\mathrm{pH}>$ mesh; and the optimization of enzymatic-assisted extraction of polysaccharides from roxburgh rose pomace were $\mathrm{A}_{1} \mathrm{~B}_{3} \mathrm{C}_{1} \mathrm{D}_{3} \mathrm{E}_{1} \mathrm{~F}_{3}$ : the enzymatic concentration was $2.5 \%$, the enzymatic hydrolysis at $60^{\circ} \mathrm{C}$ for $40 \mathrm{~min}$, the solidliquid ratio is $1: 25$, $\mathrm{pH}$ was 4 and mesh 100 .
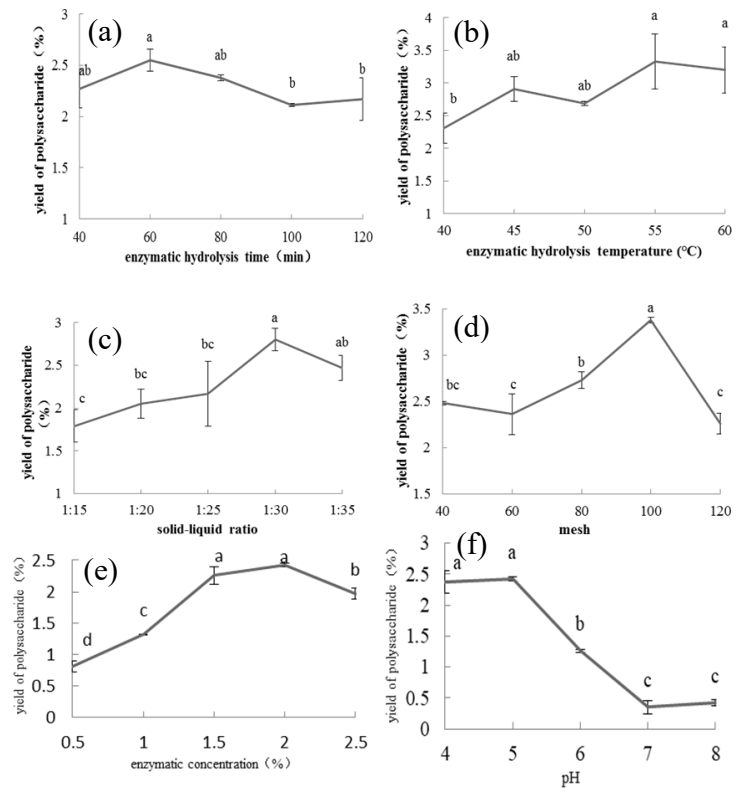

Fig.2 Effect of Single factor experiments on the yield of polysaccharide
Table2 The orthogonal experiment results analysis table

\begin{tabular}{|c|c|c|c|c|c|c|c|}
\hline number & A & B & C & D & E & F & $\begin{array}{l}\text { yield } \\
(\%)\end{array}$ \\
\hline 1 & 1 & 1 & 1 & 1 & 1 & 1 & 2.68 \\
\hline 2 & 1 & 2 & 2 & 2 & 2 & 2 & 4.21 \\
\hline 3 & 1 & 3 & 3 & 3 & 3 & 3 & 4.01 \\
\hline 4 & 2 & 1 & 1 & 2 & 2 & 3 & 2.83 \\
\hline 5 & 2 & 2 & 2 & 3 & 3 & 1 & 2.74 \\
\hline 6 & 2 & 3 & 3 & 1 & 1 & 2 & 2.97 \\
\hline 7 & 3 & 1 & 2 & 1 & 3 & 2 & 2.33 \\
\hline 8 & 3 & 2 & 3 & 2 & 1 & 3 & 2.98 \\
\hline 9 & 3 & 3 & 1 & 3 & 2 & 1 & 4.44 \\
\hline 10 & 1 & 1 & 3 & 3 & 2 & 2 & 2.81 \\
\hline 11 & 1 & 2 & 1 & 1 & 3 & 3 & 3.20 \\
\hline 12 & 1 & 3 & 2 & 2 & 1 & 1 & 3.23 \\
\hline 13 & 2 & 1 & 2 & 3 & 1 & 3 & 4.59 \\
\hline 14 & 2 & 2 & 3 & 1 & 2 & 1 & 2.55 \\
\hline 15 & 2 & 3 & 1 & 2 & 3 & 2 & 3.31 \\
\hline 16 & 3 & 1 & 3 & 2 & 3 & 1 & 3.31 \\
\hline 17 & 3 & 2 & 1 & 3 & 1 & 2 & 3.59 \\
\hline 18 & 3 & 3 & 2 & 1 & 2 & 3 & 2.13 \\
\hline $\mathrm{K}_{1}$ & 20.14 & 18.55 & 20.05 & 15.86 & 20.04 & 18.95 & \\
\hline $\mathrm{K}_{2}$ & 18.99 & 19.27 & 19.23 & 19.87 & 18.97 & 19.22 & \\
\hline $\mathrm{K}_{3}$ & 18.78 & 20.09 & 18.63 & 22.18 & 18.90 & 19.74 & \\
\hline $\mathrm{k}_{1}$ & 3.36 & 3.09 & 3.34 & 2.64 & 3.34 & 3.16 & \\
\hline $\mathrm{k}_{2}$ & 3.17 & 3.21 & 3.21 & 3.31 & 3.16 & 3.20 & \\
\hline $\mathrm{k}_{3}$ & 3.13 & 3.35 & 3.11 & 3.70 & 3.15 & 3.29 & \\
\hline $\mathrm{R}$ & 0.23 & 0.26 & 0.24 & 1.05 & 0.19 & 0.13 & \\
\hline
\end{tabular}

\subsection{Verification experiment}

The optimum enzymatic-assisted extraction conditions obtained from orthogonal experiment, the average yield of polysaccharides extracted from roxburgh rose pomace reached $(4.79 \pm 0.07) \%$ by cellulase and pectinase.

\subsection{Antioxidant analysis of polysaccharide from roxburgh rose pomace}

The antioxidant activity of polysaccharides from the roxburgh rose residue was evaluated by the color of the solution. From figure 3(a), the scavenging rate of 
hydroxyl radicals was not more than $30 \%$ in each group, and the crude polysaccharide B was significantly higher than the other groups. It shows that the polysaccharide from the residue has the ability of scavenging hydroxyl radical, but it is inferior to the polysaccharide from soybean curd residue [18], guarana powder [19] and fungal [20].

The ability of scavenging DPPH free radicals is commonly used to measure the antioxidant ability of fruits and vegetables [21]. From figure 3(b), as the concentration of polysaccharide increased gradually, the free radical scavenging rate of DPPH was significantly enhanced and not less than $60 \%$, which was better than polysaccharide from ginkgo biloba [22] and dendrobium candidum [23], lower than guarana powder [19]. The inhibition rate of DPPH free radical in the $0.1 \mathrm{mg} / \mathrm{mL}$ crude polysaccharides from the roxburgh rose residue was similar with $0.5 \mathrm{mg} / \mathrm{mL}(\mathrm{p}>0.05)$. But the scavenging ability of crude polysaccharides $B$ at high concentration was significantly higher than that of crude polysaccharide $\mathrm{A}(\mathrm{p}<0.05)$.

From figure 3(c), it can be drawn that different concentrations of crude polysaccharides from the roxburgh rose residue have a certain reduction power, but with the concentration of crude polysaccharides A increased, the reducing power has little change. The reduction power increased with the crude polysaccharide B concentration increased $(p<0.05)$. But both of them were significantly lower than roxburgh rose residue group, and superior to ginkgo biloba polysaccharides [21]. It is suggested that the electron provided by crude polysaccharides can not only reduce $\mathrm{Fe}^{3+}$ to $\mathrm{Fe}^{2+}$, but also form inert compounds with free radicals, thus avoiding self-oxidation chain reaction. However, the roxburgh rose residue group has strong reducing ability as a result of polyphenols, flavonoids and other bioactive substances.
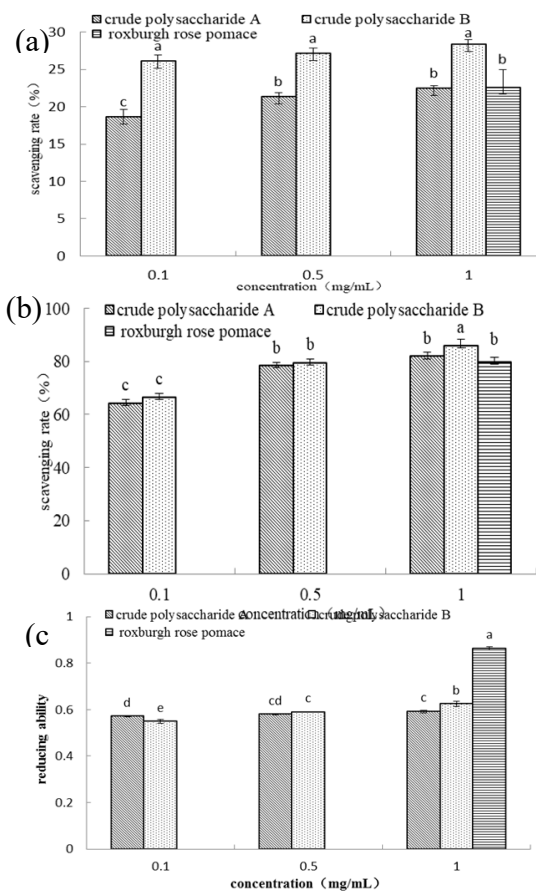

Fig.3 Comparison of the antioxidant activity of polysaccharides extracted from roxburgh rose residue

\section{Conclusion}

In this experiment, roxburgh rose juice was extracted which after roxburgh rose residue was taken as raw material. Later on we had studied the extraction process of polysaccharides from roxburgh rose pomace by enzyme assisted method. The single factor and $\mathrm{L}_{18}\left(3^{6}\right)$ orthogonal experiment were designed to study the optimal techniques on extracting of polysaccharides by cellulase and pectinase (2: 1). The optimization of enzymatic-assisted extraction of polysaccharides was as follows: mesh 100 roxburgh rose residue, add distilled water at the solid-liquid ratio $1: 25,2.5 \%$ enzymatic and adjust $\mathrm{pH}$ was 4 , hydrolysis at $60^{\circ} \mathrm{C}$ for $40 \mathrm{~min}$, mesh 100 , the average yield of polysaccharides reached $(4.79 \pm 0.071) \%$, indicating that the enzyme assisted extraction increased the yield of polysaccharides significantly. The antioxidant experiments showed that the radical scavenging rate on $\mathrm{DPPH}$ and $\mathrm{OH}$ of 1 $\mathrm{mg} / \mathrm{mL}$ polysaccharides after degreasing and deproteinization were $86.1 \%$ and $28.4 \%$, respectively, and reducing power was 0.625 . Compared with the roxburgh rose residue, the crude polysaccharide has stronger scavenging ability of DPPH free radical, yet its hydroxyl radical scavenging ability is not as good as other polysaccharides such as soybean curd residue, guarana powder. It not only provides a good idea for the rational use of roxburgh rose residue, but also provides experimental basis for the industrial production from residue polysaccharides, Therefore, it provides a new way for making full use of characteristic resources in Guizhou province. However, further researches are needed to study the relationship between its composition and antioxidant.

\section{Acknowledgements}

This research was financially supported by the Key Laboratory of functional food Project of Education Department of Guizhou Province (China) (Project KY[2016]007) and the special funding of Guiyang science and technology bureau and Guiyang University [GYU-KYZ〔2018〕01-25] for financial support.

\section{References}

1. Y. Liu, M. Qiang, Z. Sun, Y. Du, Int. J. Biol. Macromol. 80, (2015)

2. M.B. Romdhane, A. Haddar, I. Ghazala, K.B. Jeddou, C.B. Helbert, S. Ellouz-Chaabouni, Food Chem. 216, 1 (2017)

3. C.P. Zhu, X.C. Zhai, L.Q. Li, X.X. Wu, B. Li, Food Chem. 177, (2015)

4. K. Zhong, Q. Wang, Carbohydrate Polymers, 80, 1 (2010)

5. J.B. Tang, X. Xiao, J. Yang, M. Peng, J.H. Liu, Nat. Prod. Res. Dev. 27, 2 (2015)

6. F.F. Zeng, Z.S. Luo, J. Zhejiang Agr. Sci. 56, 11 (2015) 
7. F. Zhao, H.X. Niu, C.Q. Tong, Farm Prod. Process. 8, (2017)

8. Q.J. Li, Y. Nan, J.J. Qing, Y. Yang, X.J. Hao, X.S. Yang, China Journal of Chinese Materia Medica, 41, 3 (2016)

9. J.S., Hu, C.Q. Tong, L.P. Zheng, W. Li, Acad. Period. Farm Prod. Process. 3, (2017)

10. S. Wang, X. Dong, J. Tong, Int. J. Biol. Macromol. 62, 11 (2013)

11. X. Yin, Q. You, Z. Jiang, Carbohyd. Polym. 86, 3 (2011)

12. J. Chen, T. Zhang, B. Jiang, W. Mu, M. Miao, Carbohyd. Polym. 87, 1(2012)

13. Q. Zhao, B. Xie,, J. Yan,, F. Zhao, J. Xiao, L. Yao, Carbohyd. Polym. 87, 1(2012)

14. Z.Y. Cheng, H.Y. Song, Y.J. Yang, Y. Liu, Z.G. Liu, H.B. Hu, Y. Zhang, Int. J. Biol. Macromol. 76, (2015)

15. Y. Bai, L. Liu, R. Zhang, F. Huang, Y. Deng, M. Zhang, Int. J. Biol. Macromol. 96, (2017)

16. Q. Liu, Y.H. Liu, H.P. He, F. Wang, D.Y. Yao, F.F. He, H.F. Liu, Y.B. Fan, J. Mater. Chem. B, 6, (2018)

17. G.K.F. Oliveira, T.F. Tormin, R.M.F. Sousa, A.D. Oliveira, S.A.L.D. Morais, E.M. Richter, R.A.A. Munoz, Food Chem. 192, 1 (2016)

18. S. Li, L. Wang, C. Song, X.S. Hu, H.Y. Sun, Y.N. Yang, Z.F. Lei, Z.Y. Zhang, J. Taiwan Inst. Chem. E. 45, 1 (2014)

19. N. Dalonso, P. Cldo, Food Chem. 134, 4 (2012)

20. X. Xu, Y. Wu, H. Chen, Food Chem. 127, 1 (2011)

21. B.P.C. Wootton, A. Moran, L. Ryan, Food Res. Int. 44, 1(2011)

22. Q.P. Wu, H.X. Qiao, H. H. He, J.N. Hu, J. Wu, J.B. Yao, R.W. Wang, Chinese J. Mod. Appl. Pharm. 31, 1 (2014)

23. Y. Xue, L.Li, G.R.Liu, X.Y.Wang, Q.E. Wang, Sci. Technol. Food Indus. 38, 9 (2017) 